\title{
Luminal Secretion of Ammonia in the Mouse Proximal Tubule Perfused in Vitro
}

\author{
Glenn T. Nagami \\ With the technical assistance of Evelyn M. Warech \\ Nephrology Section, Research and Medical Services, Veterans Administration Medical Center West Los Angeles, \\ Los Angeles, California 90073; and Department of Medicine, School of Medicine, \\ University of California at Los Angeles, Los Angeles, California 90024
}

\begin{abstract}
A major portion of the total ammonia $\left(\mathrm{NH}_{3}=\mathrm{NH}_{3}+\mathrm{NH}_{4}^{+}\right)$ produced by the isolated perfused mouse proximal tubule is secreted into the luminal fluid. To assess the role of $\mathrm{Na}^{+}-\mathrm{H}^{+}$ exchange in net $\mathrm{tNH}_{3}$ secretion, rates of net $\mathrm{tNH}_{3}$ secretion and $\mathrm{tNH}_{3}$ production were measured in proximal tubule segments perfused with control $\mathrm{pH}$ 7.4 Krebs-Ringer bicarbonate (KRB) buffer or with modified KRB buffers containing $10 \mathrm{mM}$ sodium and $0.1 \mathrm{mM}$ amiloride. $\mathrm{Net} \mathrm{tNH}_{3}$ secretion was inhibited by $90 \%$ in proximal tubule segments perfused with the pH 7.4 modified $\mathrm{KRB}$ buffer while $\mathrm{tNH}_{3}$ production remained unaffected. The inhibition of net $\mathrm{tNH}_{3}$ secretion by perfusion with the modified KRB buffer was only partially reversed by acidifying the modified KRB luminal perfusate from 7.4 to as low as 6.2. These data indicate that the $\mathrm{Na}^{+}-\mathrm{H}^{+}$exchanger facilitates a major portion of net $\mathrm{tNH}_{3}$ secretion by the proximal tubule and that luminal acidification may play only a partial role in the mechanism by which the $\mathrm{Na}^{+}-\mathrm{H}^{+}$exchanger mediates net $\mathrm{NHH}_{3}$ secretion.
\end{abstract}

\section{Introduction}

Secretion of ammonia from within the proximal tubule cell into the luminal fluid is the initial step in ammonia handling by the nephron (1-4). Furthermore, the major fraction of the ammonia excreted by the nephron into the final urine is already present in the luminal fluid of the late proximal tubule. The factors regulating cell-to-lumen ammonia entry in the proximal tubule have not been fully explored because of the limitations inherent in techniques previously used. The standard free-flow micropuncture technique has been used to assess luminal ammonia entry in the past, but because total ammonia production rates cannot be measured using the micropuncture technique it is difficult to ascertain whether altered rates of luminal ammonia entry result from altered rates of production, from altered rates of transport, or from both. The in vitro microperfusion technique originally developed by Burg and colleagues (5) has been applied to examine transepithelial fluxes in various segments of the nephron including the proximal tubule $(6,7)$. Although this technique has provided

Address reprint requests to Dr. Nagami, Nephrology Section 691/W111L, Veterans Administration Medical Center West Los Angeles, Los Angeles, CA 90073.

Portions of this study were presented at the 43rd Annual Meeting of the American Federation for Clinical Research, May 1986, Washington, DC.

Received for publication 21 July 1986 and in revised form $24 \mathrm{Au}$ gust 1987.

The Journal of Clinical Investigation, Inc.

Volume 81, January 1988, 159-164 important information about transepithelial ammonia flux, it does not directly examine the factors which regulate cell-tolumen ammonia entry.

Recent studies from this laboratory have demonstrated that total ammonia $\left(\mathrm{NH}_{3}+\mathrm{NH}_{4}^{+}\right)$production and net luminal total ammonia secretory rates may be determined in isolated perfused mouse proximal tubule segments $(8,9)$. The total ammonia production rate represents the rate at which total ammonia leaves the perfused proximal tubule segment via the peritubular and luminal aspects of the tubule. The luminal total ammonia output rate reflects the difference between the cell-to-lumen entry rate and the rate at which total ammonia leaves the luminal fluid via cell reentry or the paracellular pathway. Thus, the luminal total ammonia output rate represents the net rate of total ammonia secretion. In our previous studies, we demonstrated that most of the total ammonia produced by a perfused proximal tubule segment is secreted into the luminal fluid and enters the bath medium via the luminal fluid leaving the distal end of the perfused segment $(8,9)$. In the present study, we examined the roles of the $\mathrm{Na}^{+}-\mathrm{H}^{+}$exchanger and intraluminal $\mathrm{pH}$ on net luminal total ammonia secretion and total ammonia production rates.

\section{Methods}

Animals. Male Swiss Webster mice (Hilltop Laboratories, Scottdale, PA) weighing 25 to $35 \mathrm{~g}$ had free access to Purina Rodent Chow (Ralston-Purina Co., St. Louis, MO) and water.

Isolation and perfusion of the individual proximal tubule segments. This method has been described in detail (8). Briefly, a mouse was killed by cervical dislocation and a kidney rapidly removed and placed in iced Krebs-Ringer bicarbonate (KRB) buffer. Proximal tubule segments consisting of the late convoluted and early straight portions from the outer cortex were dissected with needle-tipped forceps under microscopic guidance. Tubule segment lengths were measured with a calibrated eye-piece micrometer and ranged from 0.6 to $1.2 \mathrm{~mm}$. The tubules were cannulated and perfused with KRB buffer. The perfusate buffer was pregassed at $37^{\circ} \mathrm{C}$ with $95 \% \mathrm{O}_{2}: 5 \% \mathrm{CO}_{2}$ gas mixture and collected in gas-tight syringes that were mounted in a syringe pump (Sage Instruments, Cambridge, MA). The perfusates were delivered into the perfusion pipette without direct exposure to room air. The initial perfusate $\mathrm{pH}$ values reported below represent $\mathrm{pH}$ values of fluid leaving the perfusion pipette. The tubules were incubated at $37^{\circ} \mathrm{c}$ in $\sim 150 \mu \mathrm{l}$ of KRB buffer containing $0.5 \mathrm{mM}$ L-glutamine and $1.0 \mathrm{mM}$ sodium acetate pregassed with $95 \% \mathrm{O}_{2}: 5 \% \mathrm{CO}_{2}$ gas to ensure adequate stirring. At the end of the incubation period an aliquot of the bath medium was taken for measurement of total ammonia. The final bath volume was determined from the dilution of known amounts of trypan blue dye added to the perfusion chamber.

In some experiments, a second pipette was used to collect the fluid leaving the distal end of the perfused segment. The total ammonia content in timed luminal fluid collections was used to determine net rates of total ammonia secretion. 
Total ammonia assay. Total ammonia was measured using the method developed in this laboratory (8). This method was based upon a series of enzymatic reactions that were ultimately coupled with a bioluminescence reaction so that light emission was directly proportional to the amount of total ammonia in the sample. Total ammonia in the sample quantitatively reacted with excess NADH and $\alpha$-ketoglutarate in the presence of glutamic dehydrogenase to form glutamate and oxidized NAD $\left(\mathrm{NAD}^{+}\right)$. The excess NADH was destroyed by acid hydrolysis and the remaining $\mathrm{NAD}^{+}$was measured using a series of coupled enzymatic reactions involving glucose- 6 phosphate dehydrogenase, NAD:FMN oxido-reductase, and bacterial luciferase. The light emission of the processed sample was measured on a photometer (model 20; Turner Designs, Mountain View, CA). The relationship between plateau light emission rate and total ammonia concentration was linear and the coefficient of variation in the range of total ammonia concentrations observed in our samples was 0.05 to 0.1 .

Determination of luminal fluid $\mathrm{pH}$. Luminal fluid $\mathrm{pH}$ was measured using a glass pipette (10 $\mu \mathrm{m}$ tip diam) in which a liquid ion exchanger specific for hydrogen ions (World Precision Instruments, New Haven, CT) was added to the presilanized tip and back-filled with sodium phosphate buffer pH 7.0 (10). The pipette was connected via $\mathrm{Ag} / \mathrm{AgCl}$ wire to a high input impedance electrometer (FD 223; World Precision Instruments). The distal most portion of the electrode tip was desilanized with $10 \mathrm{M} \mathrm{KOH}$ so that a very small reservoir of water could be maintained at the tip thus making the electrode resistant to poisoning by mineral oil (11). The luminal fluid specimens were collected under pre-gassed mineral oil with a collection pipette. The liquid ion exchanger and $\mathrm{KCl}$ reference pipettes were directly introduced into the mineral oil and collected fluid, and advanced to the distal most portion of the collection pipette so that the tip of the liquid ion exchanger pipette was positioned at the luminal opening of the distal end of the perfused segment. The $\mathrm{pH}$ was determined from the difference between the voltages observed with the ion-specific and reference electrodes. Standard $\mathrm{pH}$ solutions measured with the two electrode system revealed a sensitivity of $56 \mathrm{mV} / \mathrm{pH}$.

Solutions. The KRB buffer contained $\mathrm{NaCl}(125 \mathrm{mM}), \mathrm{NaHCO}_{3}$ (25 mM), $\mathrm{KCl}(5 \mathrm{mM}), \mathrm{MgCl}_{2}(1.0 \mathrm{mM}), \mathrm{NaH}_{2} \mathrm{PO}_{4}(1.0 \mathrm{mM})$, and $\mathrm{CaCl}_{2}(1.0 \mathrm{mM})$. As described below, in some experiments, the sodium concentration of the perfusate buffer was reduced to $10 \mathrm{mM}$ by isoosmotically replacing sodium chloride with mannitol and partially replacing sodium bicarbonate with choline bicarbonate $(16 \mathrm{mM}$ choline bicarbonate and $9 \mathrm{mM}$ sodium bicarbonate). The $\mathrm{pH}$ of the perfusate was lowered in certain experiments by reducing the bicarbonate concentration and raising the chloride concentration by an equivalent degree.

Calculations. Total ammonia production rates (picomoles per minute per millimeter) were calculated from the bath total ammonia concentration, bath volume, incubation time, and tubule segment length, as described before (8). Luminal total ammonia output rates were calculated from the total ammonia content of timed luminal fluid samples (8). Since the luminal total ammonia output rate was the difference between the rate of total ammonia addition to the luminal fluid and the rate of total ammonia removal from the luminal fluid, the luminal total ammonia output rate represented the net total ammonia secretory rate. Flow rates were determined by the rate that known amounts of $\left[{ }^{3} \mathrm{H}\right]$ methoxyinulin left the distal end of the perfused segment.

Data are presented as mean \pm SE. Comparisons between two groups of data were made using Student's $t$ test and comparisons among more than two groups of data were made using a single analysis of variance with multiple comparisons among groups of varying size (Sheffe's method) (12).

\section{Results}

Under the experimental conditions, total ammonia production and net total ammonia secretion remained stable for up to
$60 \mathrm{~min}$ of incubation at $37^{\circ} \mathrm{C}$. All measurements were obtained within $60 \mathrm{~min}$ after dissection. All tubules excluded trypan blue. Flow rates in the groups of tubules ranged from 20.3 to $22.4 \mathrm{nl} / \mathrm{min}$ and there were no statistically significant differences in mean flow rates among the groups. The lengths of individual tubule segments ranged from 0.6 to $1.2 \mathrm{~mm}$ with no statistically significant differences in the mean segment length among the groups studied. The mean length of tubules in this study was $0.86 \mathrm{~mm}$.

Total ammonia production and net total ammonia secretion rates were measured in tubules bathed in $\mathrm{pH} 7.4 \mathrm{KRB}$ buffer containing $0.5 \mathrm{mM}$ L-glutamine and $1.0 \mathrm{mM}$ sodium acetate and perfused with the control $\mathrm{pH} 7.4 \mathrm{KRB}$ buffer or with a modified KRB buffer in which $0.1 \mathrm{mM}$ amiloride was added and the sodium concentration was reduced to $10 \mathrm{mM}$ by isoosmotically replacing sodium chloride with mannitol and partially replacing sodium bicarbonate with choline bicarbonate. Perfusion with the modified KRB buffer containing 10 $\mathrm{mM}$ sodium and $0.1 \mathrm{mM}$ amiloride inhibited the rate of fluid reabsorption by 5 proximal tubule segments $(0.1 \pm 0.1 \mathrm{nl} / \mathrm{min}$ per $\mathrm{mm}$ with the modified KRB perfusate versus $0.8 \pm 0.2 \mathrm{nl} /$ min per $\mathrm{mm}$ with control KRB perfusate) at flow rates of 21 $\mathrm{nl} / \mathrm{min}$. Perfusion with the modified KRB buffer also inhibited measurable luminal fluid acidification. The collected fluid $\mathrm{pH}$ was $7.27 \pm 0.01$ in five tubules perfused with the control KRB buffer (initial $\mathrm{pH} 7.43 \pm 0.01$ ) and was $7.44 \pm 0.01$ in five tubules perfused with the modified KRB buffer (initial pH $=7.43 \pm 0.01$ ) at flow rates of $21 \mathrm{nl} / \mathrm{min}$. Proximal tubule segments perfused with the control buffer at a flow rate of $20.9 \pm 0.4 \mathrm{nl} / \mathrm{min}$ produced total ammonia at a rate of $21.0 \pm 0.5 \mathrm{pmol} / \mathrm{min}$ per $\mathrm{mm}$, which was not significantly different from the rate observed in segments perfused with the modified KRB buffer at a flow rate of $21.0 \pm 0.5 \mathrm{nl} / \mathrm{min}$, $21.0 \pm 0.4 \mathrm{pmol} / \mathrm{min}$ per $\mathrm{mm}$ (Fig. 1). The rate of net total ammonia secretion was $11.3 \pm 0.3 \mathrm{pmol} / \mathrm{min}$ per $\mathrm{mm}$ in tubules perfused with the control KRB perfusate, while it was only $1.0 \pm 0.2 \mathrm{pmol} / \mathrm{min}$ per $\mathrm{mm}$ in tubules perfused with the modified KRB buffer. Thus perfusion with the modified KRB buffer containing $10 \mathrm{mM}$ sodium and $0.1 \mathrm{mM}$ amiloride markedly diminished net total ammonia secretion without significantly affecting total ammonia production (Fig. 1).

To assess the importance of luminal acidity on total ammonia production and net secretion of total ammonia, proximal tubule segments were perfused with the $10 \mathrm{mM}$ sodium buffer containing $0.1 \mathrm{mM}$ amiloride in which the $\mathrm{pH}$ was lowered by reducing the bicarbonate concentration while maintaining a constant sodium concentration of $10 \mathrm{mM}$. The $\mathrm{pH}$ of the collected luminal fluid of perfused proximal tubule segments was measured when the segments were perfused with pH 7.4 KRB control perfusate (group I) or with the modified KRB buffers containing $10 \mathrm{mM}$ sodium, $0.1 \mathrm{mM}$ amiloride and either $25 \mathrm{mM}$ (group II), $5 \mathrm{mM}$ (group III) or $1.2 \mathrm{mM}$ (group IV) bicarbonate (Table I). Perfusion flow rates did not differ among the groups averaging $21.2 \pm 0.5 \mathrm{nl} / \mathrm{min}$. The $\mathrm{pH}$ of collected fluid samples of proximal segments perfused with the modified KRB buffer containing $1.2 \mathrm{mM}$ bicarbonate was significantly lower than the tubules perfused with control KRB buffer $(P<0.01)$ or with the modified KRB buffer containing $25 \mathrm{mM}$ bicarbonate $(P<0.01)$. The $\mathrm{pH}$ of luminal fluid samples of segments perfused with the modified KRB buffer containing $5 \mathrm{mM}$ bicarbonate was significantly lower than the $\mathrm{pH}$ 


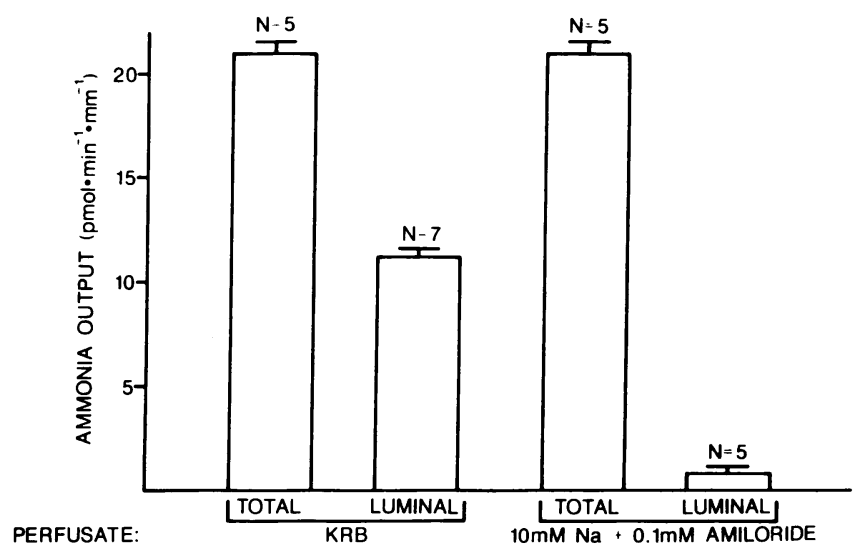

Figure 1. Luminal total ammonia output and total ammonia production rates by mouse proximal tubules bathed in $\mathrm{pH}$ 7.4 KRB buffer and perfused with either control pH 7.4 KRB buffer or with pH 7.4 modified KRB buffer containing $10 \mathrm{mM}$ sodium and 0.1 $\mathrm{mM}$ amiloride.

of luminal fluid from tubules perfused with the modified KRB buffer containing $25 \mathrm{mM}$ bicarbonate, but did not differ significantly from the $\mathrm{pH}$ of luminal fluid from tubules perfused with the control KRB buffer. Total ammonia production rates did not significantly differ among the four groups of tubules perfused with the various perfusates (Table I).

The net total ammonia secretion rates were measured in tubules perfused with control KRB buffer and with modified KRB buffers containing $10 \mathrm{mM}$ sodium, $0.1 \mathrm{mM}$ amiloride, and various concentrations of bicarbonate. Perfusion flow rates did not differ significantly among groups and averaged $21.0 \pm 1.0 \mathrm{nl} / \mathrm{min}$. The net rates of total ammonia secretion observed in tubules perfused with the modified KRB buffers containing $10 \mathrm{mM}$ sodium buffer and $0.1 \mathrm{mM}$ amiloride were higher in the groups perfused with the modified KRB buffers containing 1.2 or $5 \mathrm{mM}$ bicarbonate concentrations than in the group perfused with the modified KRB buffer containing $25 \mathrm{mM}$ bicarbonate (Fig. 2). The net rate of total ammonia secretion of proximal tubule segments perfused with the modified KRB buffer containing $5 \mathrm{mM}$ bicarbonate was $3.5 \pm 0.4$ $\mathrm{pmol} / \mathrm{min}$ per $\mathrm{mm}$, and the net rate of secretion observed in tubule segments perfused with the modified KRB buffer containing $1.2 \mathrm{mM}$ bicarbonate was $9.1 \pm 0.5 \mathrm{pmol} / \mathrm{min}$ per $\mathrm{mm}$.

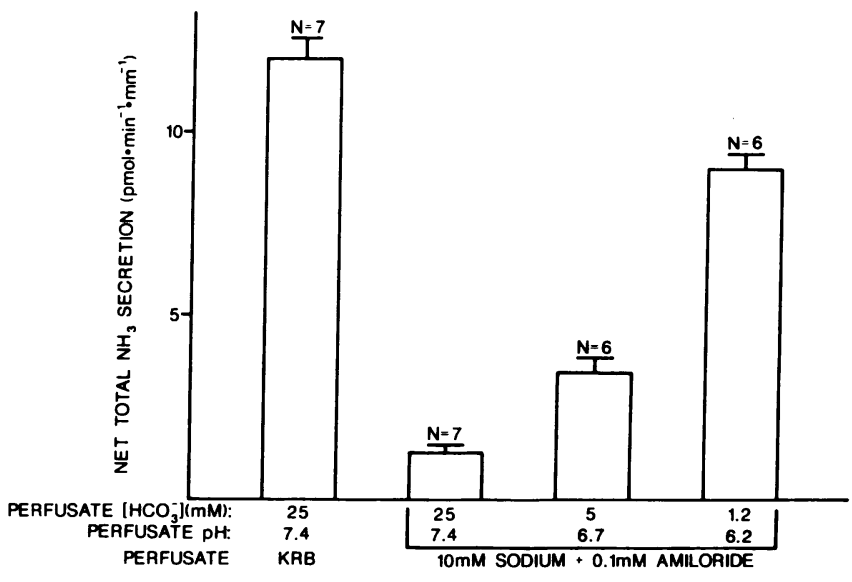

Figure 2. Net luminal secretion of total ammonia in proximal tubule segments bathed in pH 7.4 KRB buffer and perfused with KRB buffer ( $\mathrm{pH} 7.4,\left[\mathrm{HCO}_{3}^{-}\right]=25 \mathrm{mM}$ ) or with various modified $\mathrm{KRB}$ buffers containing $10 \mathrm{mM}$ sodium and $0.1 \mathrm{mM}$ amiloride.

The rates of total ammonia secretion observed in tubules perfused with $5 \mathrm{mM}$ and $1.2 \mathrm{mM}$ bicarbonate buffers were significantly higher than the net rate observed in tubules perfused with the modified KRB buffer containing $25 \mathrm{mM}$ bicarbonate, $1.3 \pm 0.2 \mathrm{pmol} / \mathrm{min}$ per $\mathrm{mm}(P<0.05$ vs. the $5-\mathrm{mM}$ bicarbonate group and $P<0.01 \mathrm{vs.} 1.2 \mathrm{mM}$ bicarbonate group), but remained lower than the rate observed in tubules perfused with the control KRB perfusate, $12.0 \pm 0.6 \mathrm{pmol} / \mathrm{min}$ per $\mathrm{mm}(P$ $<0.01)$. Thus lowering the bicarbonate concentration and $\mathrm{pH}$ of the modified KRB perfusate containing $10 \mathrm{mM}$ sodium and $0.1 \mathrm{mM}$ amiloride increased the net secretion of total ammonia without significantly altering the rate of total ammonia production. Nevertheless, lowering the luminal $\mathrm{pH}$ of the modified KRB perfusate containing $10 \mathrm{mM}$ sodium and 0.1 $\mathrm{mM}$ amiloride from 7.4 to as low as 6.2 failed to bring the net luminal total ammonia secretory rate up to the level observed in tubules perfused with control $\mathrm{pH} 7.4 \mathrm{KRB}$ buffer.

Because it is unclear whether functional luminal carbonic anhydrase is present in the segment of the mouse proximal that we studied (13), it is also unknown whether an acid disequilibrium $\mathrm{pH}$ is present. Such a disequilibrium $\mathrm{pH}$ would not be detected by measuring the $\mathrm{pH}$ of the collected fluid. If present, an acid disequilibrium $\mathrm{pH}$ would enhance the net

Table I. Total Ammonia Production Rates by Proximal Tubules Perfused with Control KRB Buffer and Modified KRB Buffers Containing $10 \mathrm{mM}$ Sodium and $0.1 \mathrm{mM}$ Amiloride

\begin{tabular}{|c|c|c|c|c|c|c|}
\hline Group & Perfusate & $n$ & Perfusate $\mathrm{HCO}_{3}^{-}$ & Perfusate pH & Collected fluid pH & Total ammonia production \\
\hline & & & $m M$ & & & $\mathrm{pmol} / \mathrm{min}$ per $\mathrm{mm}$ \\
\hline I & Control KRB buffer & 7 & 25 & $7.43 \pm 0.01$ & $7.37 \pm 0.01$ & $20.5 \pm 0.7$ \\
\hline II & Low $\mathrm{Na}+$ amiloride & 6 & 25 & $7.43 \pm 0.01$ & $7.44 \pm 0.02^{*}$ & $22.1 \pm 0.6$ \\
\hline III & Low $\mathrm{Na}+$ amiloride & 6 & 5 & $6.74 \pm 0.01^{\S}$ & $7.33 \pm 0.01^{* \ddagger}$ & $20.5 \pm 1.5$ \\
\hline IV & Low $\mathrm{Na}+$ amiloride & 6 & 1.2 & $6.18 \pm 0.01^{8}$ & $7.23 \pm 0.01^{8}$ & $20.4 \pm 1.9$ \\
\hline
\end{tabular}

${ }^{*} P<0.05$ vs. group I. ${ }^{\ddagger} P<0.01$ vs. group II. ${ }^{\S} P<0.001$ vs. group I and group II. 
secretion of total ammonia by permitting diffusable nonionic ammonia to be trapped as ammonium ion within the acidic luminal fluid. An acid disequilibrium $\mathrm{pH}$ would also explain the marked reduction of net total ammonia secretion by the inhibition of luminal acidification by perfusion of the tubule lumen ith the modified KRB buffer containing $10 \mathrm{mM}$ sodium and $0.1 \mathrm{mM}$ amiloride as described above. We added carbonic anhydrase (bovine type 2; Sigma Chemical Co., St. Louis, MO) to the luminal perfusate $\left(0.1 \mathrm{mg} / \mathrm{cm}^{3}\right)$ to eliminate any disequilibrium $\mathrm{pH}(14)$ and measured net total ammonia secretion in the presence and absence of carbonic anhydrase in the luminal perfusate (Fig. 3). Net total ammonia secretion in tubules perfused with KRB buffer containing carbonic anhydrase was $9.9 \pm 0.4 \mathrm{pmol} / \mathrm{min}$ per $\mathrm{mm}$, which was $15 \%$ lower than the rate observed in control proximal tubule segments perfused at a similar flow rate with KRB buffer without carbonic anhydrase $(P<0.01)$. The total ammonia production rate in 6 tubules perfused with carbonic anhydrase was $21.5 \pm 1.3 \mathrm{pmol} / \mathrm{min}$ per $\mathrm{mm}$ which did not differ significantly from 7 tubules perfused with KRB control buffer without carbonic anhydrase. Thus, addition of carbonic anhydrase to the perfusate produced only a small suppression in net total ammonia secretion without affecting total ammonia production rates.

\section{Discussion}

The present study used the technique of in vitro microperfusion to measure the release of total ammonia from isolated perfused mouse proximal tubule segments. The total ammonia production rate reflected the rate at which total ammonia was released into the bath medium from both peritubular and luminal aspects of the perfused tubule segment. The net rate of luminal total ammonia secretion equaled the rate at which total ammonia left the distal end of the perfused segment in timed luminal fluid collections. The net total ammonia secretory rate reflected the difference between the rate that total ammonia entered the luminal fluid and the rate that total ammonia moved out of the luminal fluid either through cellular reentry or a paracellular pathway.

Our previous studies demonstrated that a major portion of the total ammonia produced by a perfused proximal tubule segment exits the tubule via the luminal fluid leaving the distal end of the segment $(8,9)$. The high rates of luminal total

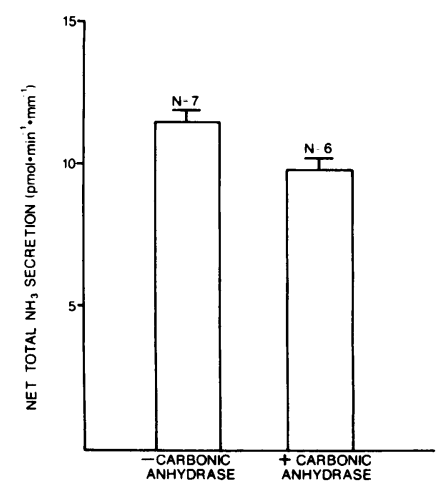

Figure 3. Net luminal secretion of total ammonia in proximal tubule segments bathed in $\mathrm{pH} 7.4 \mathrm{KRB}$ buffer and perfused with $\mathrm{pH} 7.4 \mathrm{KRB}$ buffer with or without carbonic anhydrase. ammonia secretion were remarkable in that they resulted from much higher concentrations of total ammonia appearing in collected luminal fluid samples than in the surrounding bath medium with luminal fluid-to-bath total ammonia concentration ratios exceeding 200:1. Because total ammonia appeared to enter the luminal fluid at a substantial rate despite a more favorable diffusion gradient toward the bath solution, we suggested that total ammonia secretion into the luminal fluid occurred more readily than movement into the peritubular fluid. To explore further the mechanism of net luminal total ammonia secretion, we studied the effect of the inhibition of luminal $\mathrm{Na}^{+}-\mathrm{H}^{+}$exchange on luminal total ammonia output and luminal total ammonia production.

The results of the present study suggested an important role of the $\mathrm{Na}^{+}-\mathrm{H}^{+}$exchanger in net luminal total ammonia secretion. Perfusion with a modified KRB buffer containing $10 \mathrm{mM}$ sodium and $0.1 \mathrm{mM}$ amiloride inhibited measurable acidification of the luminal fluid presumably by inhibition of $\mathrm{Na}^{+}-\mathrm{H}^{+}$exchange. Previous studies by others in rabbit brush border membrane vesicles (15) and in the rat proximal tubule perfused in vivo (16) have demonstrated the inhibitory effect of amiloride $\mathrm{Na}^{+}-\mathrm{H}^{+}$exchange and on fluid reabsorption. In the present study, when proximal tubule segments were perfused with the modified KRB buffer containing $10 \mathrm{mM}$ sodium and $0.1 \mathrm{mM}$ amiloride, the net rate of luminal total ammonia secretion was only $10 \%$ of the rate observed in tubules perfused with control KRB buffer. In contrast, the total ammonia production rate in proximal tubules perfused with the modified KRB buffer remained at control levels. Thus, the overall rate of total ammonia released by the proximal tubule was unaffected by the inhibition of the $\mathrm{Na}^{+}-\mathrm{H}^{+}$exchanger whereas the net luminal secretion of total ammonia was markedly inhibited. Inhibition of $\mathrm{Na}^{+}-\mathrm{H}^{+}$exchange could theoretically affect luminal total ammonia entry by two mechanisms: (a) inhibition of the acidification process through inhibition of $\mathrm{Na}^{+}-\mathrm{H}^{+}$exchange which would diminish trapping of ammonia as ammonium ion (17); and (b) inhibition of sodium-ammonium ion exchange (18).

According to the diffusion trapping model, the movement of total ammonia across the luminal membrane would occur by diffusion of nonionic ammonia across the luminal membrane into the luminal fluid. Accumulation of total ammonia within the luminal field would be driven by an acidic luminal fluid $\mathrm{pH}$ which would promote the titration of nonionic ammonia to ammonium ion. Ammonium ion would be trapped within the lumen because it presumably would not diffuse out of the luminal fluid via back diffusion through the luminal membrane. To determine the relative importance of luminal acidity on luminal ammonia entry, proximal tubule segments were perfused with low sodium perfusates containing amiloride in which the $\mathrm{pH}$ of the perfusate was lowered in a graded fashion by lowering the bicarbonate concentration. The reduction of the $\mathrm{pH}$ of the low sodium perfusates containing amiloride reduced collected fluid $\mathrm{pH}$ compared to collected fluid $\mathrm{pH}$ in proximal tubules perfused with $\mathrm{pH} 7.4 \mathrm{KRB}$ buffer containing $151 \mathrm{mM}$ sodium without amiloride. The reduction in collected fluid $\mathrm{pH}$ was not as great as was previously reported by us using KRB buffer with normal sodium concentrations in which the initial bicarbonate concentration was lowered to the same extent (9). In our previous study, lowering 
the bicarbonate concentration of the KRB perfusate from 25 to 5 or $1.2 \mathrm{mM}$ lowered the collected fluid $\mathrm{pH}$ from 7.34 to 6.97 or 6.75 , respectively. The higher $\mathrm{pH}$ values observed with perfusion with the low sodium perfusates containing amiloride compared with perfusion with the high sodium perfusates may have resulted from inhibition of luminal acidification in tubules perfused with the low sodium perfusates containing amiloride.

Net total ammonia secretory rates increased as the $\mathrm{pH}$ and bicarbonate concentrations were lowered in the low sodium perfusates containing amiloride while total ammonia production rates remained unchanged. Yet the net rates of total ammonia secretion did not return to the levels observed in tubules perfused with control $\mathrm{pH} 7.4 \mathrm{KRB}$ buffer without amiloride even though the collected luminal fluid and average luminal fluid $\mathrm{pH}$ of the segments perfused with the low $\mathrm{pH}$ perfusates containing $10 \mathrm{mM}$ sodium and $0.1 \mathrm{mM}$ amiloride were lower than those observed in tubules perfused with pH 7.4 control KRB perfusate. These data demonstrated that luminal acidity by itself was not the only driving force in determining the rate of net total ammonia secretion and that the mechanism by which the inhibition of the $\mathrm{Na}^{+}-\mathrm{H}^{+}$exchanger reduced net total ammonia secretion may be through the direct inhibition of the exchange of sodium for ammonium ions on the $\mathrm{Na}^{+}-\mathrm{H}^{+}$ exchanger (18).

An absence of carbonic anhydrase in contact with the luminal fluid could generate an acid disequilibrium $\mathrm{pH}$ which would result in lower intraluminal $\mathrm{pH}$ values than would be evident by $\mathrm{pH}$ measurements in collected luminal fluid samples. Such a reduced intraluminal $\mathrm{pH}$ would favor trapping of total ammonia within the luminal fluid as ammonium ion. It is not clear how much carbonic anhydrase is in contact with the luminal fluid of the mouse proximal tubule segments employed in the present studies although histologic studies suggest carbonic anhydrase may be present in the cells of the late convoluted and early straight portions of the mouse proximal tubule (13). Addition of carbonic anhydrase to the luminal fluid would abolish the disequilibrium $\mathrm{pH}$, if present, and should reduce luminal total ammonia entry dependent upon nonionic diffusion of ammonia into the lumen and trapping of ammonium ion within the lumen (14). The present studies demonstrated only a $15 \%$ reduction in net total ammonia secretion with addition of carbonic anhydrase to the perfusate suggesting that a disequilibrium $\mathrm{pH}$ played only a minor role in net total ammonia secretion under these experimental conditions.

The relative contribution of sodium-ammonium ion exchange and diffusion-trapping on net total ammonia secretion may depend upon intraluminal $\mathrm{pH}$. At an initial luminal $\mathrm{pH}$ of 7.4 and bath $\mathrm{pH}$ of 7.4 , conditions that approximate intraluminal and peritubular $\mathrm{pH}$ in the very early segments of the proximal tubule, $\mathrm{Na}^{+}-\mathrm{H}^{+}$exchanger activity would be quite active because of the large lumen-to-cell sodium gradient and cell-to-lumen hydrogen ion gradient. Under such conditions, secretion of the total ammonia made within the proximal tubule cell would be greatly facilitated by $\mathrm{Na}^{+}-\mathrm{NH}_{4}^{+}$exchange but not by diffusion of nonionic ammonia with trapping of ammonium ion which requires a favorable $\mathrm{pH}$ gradient. At low intraluminal $\mathrm{pH}$ values, conditions which may be observed in the late proximal tubule, $\mathrm{Na}^{+}-\mathrm{H}^{+}$exchanger activity may be minimal (19), but diffusion of $\mathrm{NH}_{3}$ and trapping of $\mathrm{NH}_{4}^{+}$within the lumen may be the dominant process in luminal total ammonia secretion. Consistent with this concept are the results of micropuncture studies by Good and colleagues (20) that demonstrate the generation of relatively large total ammonia concentrations within the lumen in the earliest portions of the proximal tubule even in the absence of large lumen-to-blood pH gradients.

In conclusion, a major portion of the total ammonia produced by an isolated perfused mouse proximal tubule segment leaves the tubule via the luminal fluid. Net total ammonia secretion was markedly inhibited by perfusing proximal tubule segments with a low sodium buffer containing amiloride, and this inhibition was only partially reversed by acidifying the luminal fluid. When a proximal tubule segment is perfused with and bathed in buffers with the same $\mathrm{pH}$ of 7.4 , the major mechanism by which the $\mathrm{Na}^{+}-\mathrm{H}^{+}$exchanger facilitates secretion of total ammonia into the lumen may be through $\mathrm{Na}^{+}$$\mathrm{NH}_{4}^{+}$exchange.

\section{Acknowledgments}

I am grateful to Dr. George Sachs for his encouragement and critical comments during this study.

This research was supported by the Veterans Administration, by a grant-in-aid from the American Heart Association with funds partly contributed by its Florida Affiliate, and, in part, by a grant from the National Institute of Diabetes and Digestive and Kidney Diseases (DK 38463-01). Dr. Nagami is a Research Associate of the Veterans Administration.

\section{References}

1. Glabman, S., R. M. Klose, and G. Giebisch. 1963. Micropuncture study of ammonia excretion in the rat. Am. J. Physiol. 205:127132.

2. Hayes, C. P., Jr., J. S. Mayson, E. E. Owen, and R. R. Robinson. 1964. A micropuncture evaluation of renal ammonia excretion in the rat. Am. J. Physiol. 207:77-83.

3. Sajo, I. M., M. B. Goldstein, H. Sonnenberg, B. J. Stinebaugh, D. R. Wilson, and M. L. Halperin. 1981. Sites of ammonia addition to tubular fluid in rats with chronic metabolic acidosis. Kidney Int. 20:353-358.

4. Buerkert, J., D. Martin, and D. Trigg. 1982. Ammonia handling by superficial and juxtamedullary nephrons in the rat. J. Clin. Invest. 70:1-12.

5. Burg, M. B., J. J. Grantham, M. Abramow, and J. Orloff. 1966. Preparation and study of fragments of single rabbit nephrons. Am. J. Physiol. 210:1293-1298.

6. Hamm, L. L., D. Trigg, D. Martin, C. Gillespie, and J. Buerkert. 1985. Transport of ammonia in the rabbit cortical collecting tubule. $J$. Clin. Invest. 75:478-485.

7. Garvin, J. L., M. B. Burg, and M. A. Knepper. 1986. Mechanism of transepithelial ammonia transport in rabbit proximal straight tubule. Kidney Int. 29:366. (Abstr.)

8. Nagami, G. T., and K. Kurokawa. 1985. Regulation of ammonia production by mouse proximal tubules perfused in vitro. Effect of luminal perfusion. J. Clin. Invest. 75:844-849.

9. Nagami, G. T., C. M. Sonu, and K. Kurokawa. 1986. Ammonia production by isolated mouse proximal tubules perfused in vitro. Effect of metabolic acidosis. J. Clin. Invest. 78:124-129.

10. Ammann, D., F. Lanter, R. A. Steiner, P. Schulthess, Y. Shijo, and W. Simon. 1981. Neutral carrier-based hydrogen ion selective 
microelectrode for extra- and intracellular studies. Anal. Chem. 53:2267-2269.

11. Vogel, G. L. 1985. Construction of liquid-filled ion-selective microelectrodes resistant to poisoning by mineral oil and other nonaqueous fluids. WPInfoletter. Winter 1985. World Precision Instruments, New Haven, CT. 1-2.

12. Scheffe, H. 1959. The Analysis of Variance. John Wiley \& Sons, Inc., New York, pp. 1-477.

13. Dobyan, D. C., L. S. Magill, P. A. Friedman, S. C. Hebert, and R. E. Bulger. 1982. Carbonic anhydrase histochemistry in the rabbit and mouse kidneys. Anat. Record. 204:185-197.

14. Knepper, M. A., D. W. Good, and M. B. Burg. 1984. Mechanism of ammonia secretion by cortical collecting ducts of rabbits. Am. J. Physiol. 247:F729-F738.

15. Kinsella, J. L., and P. S. Aronson. 1981. Amiloride inhibition of $\mathrm{Na}^{+}-\mathrm{H}^{+}$exchanger in renal microvillus membrane vesicles. Am. $J$. Physiol. 241:F374-F379.
16. Chan, Y. L., and G. Giebisch. 1981. Relationship between sodium and bicarbonate transport in the rat proximal convoluted tubule. Am. J. Physiol. 240:F222-F230.

17. Pitts, R. F. 1973. Production and excretion of ammonia in relation to acid-base regulation. In Handbook of Physiology, Section 8: Renal Physiology. J. Orloff and R. W. Berliner, editors. American Physiological Society, Wash DC. 455-496.

18. Kinsella, J. L., and P. S. Aronson. 1981. Interaction of $\mathrm{NH}_{4}^{+}$ and $\mathrm{Li}^{+}$with the renal microvillus membrane $\mathrm{Na}^{+}-\mathrm{H}^{+}$exchanger. $A m$. J. Physiol. 241:C220-C226.

19. Aronson, P. S., M. A. Suhm, and J. Nee. 1983. Interaction of external $\mathrm{H}^{+}$with the $\mathrm{Na}^{+}-\mathrm{H}^{+}$exchanger in renal microvillus membrane vesicles. J. Biol. Chem. 258:6767-6771.

20. Good, D. W., C. R. Caflisch, and T. D. DuBose. 1986. Effect of chronic metabolic acidosis (MA) on ammonia transport by rat proximal convoluted tubule (PT) in vivo. Clin. Res. 34:697a. (Abstr.) 